10

\title{
Оптические и фотолюминесцентные свойства тонкопленочной структуры ZnO-ЦтСЛ в ультрафиолетовом и видимом диапазонах спектра
}

\author{
(С) Л.В. Григорьев ${ }^{1,2}$, Я.Б. Егорова ${ }^{1}$, Н.А. Быков ${ }^{1}$, А.А. Семенов ${ }^{2}$, А.А. Никитин ${ }^{2}$ \\ ${ }^{1}$ Университет ИТМО, \\ 197101 Санкт-Петербург, Россия \\ ${ }^{2}$ СПбГЭТу „лЭТИ“, \\ 197022 Санкт-Петербург, Россия \\ e-mail: grigoryev@oi.ifmo.ru
}

Поступила в редакцию 29.06.2019 г.

В окончательной редакции 29.06.2019 г.

Принята к публикации 12.07.2019 г.

\begin{abstract}
Представлены результаты исследования структурных, оптических и фотолюминесцентных свойств тонкопленочной структуры $\mathrm{ZnO}$-сегнетоэлектрическая керамика ЦТСЛ. Приведены результаты рентгеноструктурного анализа пленки оксида цинка, синтезированной на подложке из ЦТСЛ и на кварцевой подложке. Приведены спектры пропускания, отражения и поглощения и спектральная зависимость фотолюминесценции тонкопленочной структуры $\mathrm{ZnO}-Ц$ ССЛ и структуры $\mathrm{ZnO}-\mathrm{SiO}_{2}$ в ультрафиолетовом и видимом диапазонах спектра.
\end{abstract}

Ключевые слова: оксид цинка, сегнетоэлектрик, спектр пропускания, спектр отражения, спектр фотолюминесценции, электронно-лучевой метод.

DOI: 10.21883/OS.2019.12.48697.226-19

\section{Введение}

Исследование физических свойств структур полупроводник-сегнетоэлектрик на основе оксида цинка $(\mathrm{ZnO})$ привлекает большое внимание исследователей, что обусловлено возможностью создания быстродействующих микроэлектронных датчиков ультрафиолетового (УФ) излучения $[1,2]$. Такие сенсоры УФ излучения могут работать в составе волоконно-оптических устройств радиофотоники. Необходимость исследования оптических свойств структуры полупроводник-сегнетоэлектрик, содержащей слой $\mathrm{ZnO}$ на различных сегнетоэлектрических подложках, обусловлена возможностью создания оптически управляемой структуры полевого транзистора.

В работе представлены результаты исследования структурных, оптических и фотолюминесцентных свойств тонкопленочной структуры $\mathrm{ZnO}$-керамика цирконий-титан-свинец, легированной лантаном (ЦТСЛ), и структуры тонкая пленка $\mathrm{ZnO}$ - диоксид кремния $\left(\mathrm{ZnO}-\mathrm{SiO}_{2}\right)$.

\section{Изготовление образцов}

Тонкопленочные структуры $\mathrm{ZnO}-Ц$ ССЛ создавались на основе полированных пластин из керамики ЦТСЛ. Керамические пластины формировались методом горячего прессования из предварительно синтезированного порошка ЦТСЛ стехиометрического состава. Структура $\mathrm{ZnO}-\mathrm{SiO}_{2}$ формировалась на поверхности полированных кварцевых пластин из кварца марки КУ-1. Поверх- ность керамических и кварцевых пластин подвергалась полировке по 12 классу чистоты. Перед операцией нанесения на поверхность подложки слоя из оксида цинка все подложки очищались от органических загрязнений в полярных и неполярных растворителях. Далее подложки промывались в деионизованной воде, удельное сопротивление которой было не менее $1.0 \mathrm{M} \Omega$. Для финишной очистки от следов загрязнений, а также с целью повышения адгезии подложки к наносимой пленке из $\mathrm{ZnO}$ все подложки подвергались ионной бомбардировке в аргонокислородной плазме. Затем рабочий объем откачивался до давления, не превышающего $10^{-3} \mathrm{~Pa}$. Слой $\mathrm{ZnO}$ на поверхности подложек формировался методом импульсного электронно-лучевого испарения мишени-таблетки из порошка $\mathrm{ZnO}$ марки ОСЧ [3]. Контроль толщины напыляемой пленки осуществлялся с помощью кварцевых микровесов. В результате импульсного электроннолучевого напыления на поверхности подложек сформировался слой из $\mathrm{ZnO}$ толщиной $2.5 \mu \mathrm{m}$.

\section{Экспериментальные результаты}

Рентгеноструктурные исследования проводились на дифрактометре ДРОН-3М с излучением $\mathrm{CuK}_{\alpha}=1.542 \AA$, анодное напряжение рентгеновской трубки составляло $25 \mathrm{kV}$. Сканирование проводилось в диапазоне брэгговских углов $2 \theta$, от 20 до $60^{\circ}$, с шагом $\Delta 2 \theta=0.05^{\circ}$. Время накопления импульсов в точке измерения составляло $15 \mathrm{~s}$. 

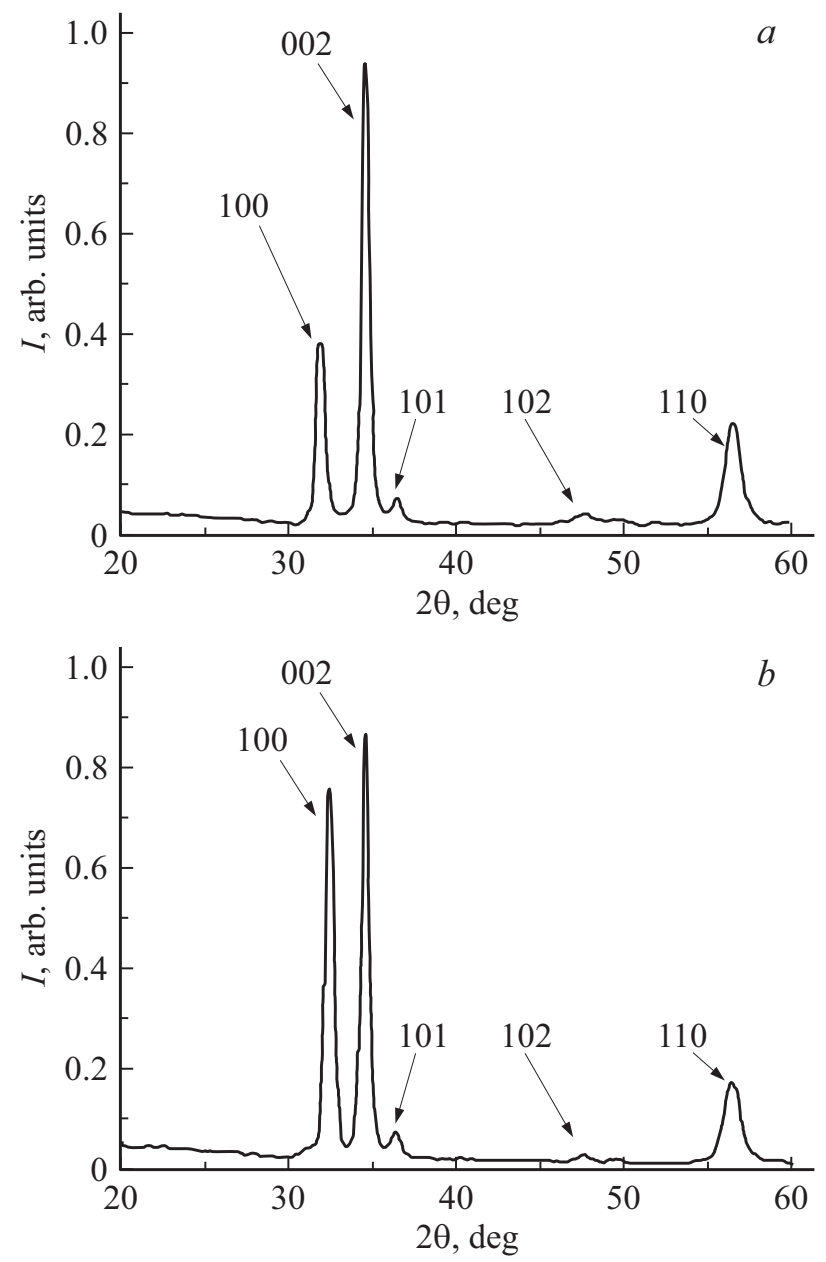

Pис. 1. Дифрактограммы тонкой пленки $\mathrm{ZnO}$ в структурах $\mathrm{ZnO}-$ кварц $(a)$ и $\mathrm{ZnO}-Ц Т С Л ~(b)$.

Дифрактограммы пленок $\mathrm{ZnO}$, структур $\mathrm{ZnO}-\mathrm{SiO}_{2}$, $\mathrm{ZnO}$-ЦТСЛ, синтезированных методом импульсного электронно-лучевого напыления, приведены на рис. 1. Аналогично результатам, представленным в работе [4], пленки $\mathrm{ZnO}$ на кварцевых подложках имеют малую плотность структурных дефектов, находящихся на границе раздела диоксид кремния-оксид цинка. Поэтому дифрактограмма слоя $\mathrm{ZnO}$ в структуре $\mathrm{ZnO}-\mathrm{SiO}_{2}$ (рис. 1,a) была принята за эталон при последующем сравнении с ней структурных свойств образцов $\mathrm{ZnO}-$ ЦТСЛ.

На всех дифрактограммах (рис. $1, a, b$ ) присутствует дифракционный максимум большой интенсивности, характерный для гексагонального $\mathrm{ZnO}(002)$, свидетельствующий о структурном совершенстве синтезируемых пленок и наличии выделенной осевой текстуры в направлении оси, перпендикулярной поверхности подложки [4].

При импульсном электронно-лучевом методе напыления слоя $\mathrm{ZnO}$ на различные подложки наблюдается изменение интенсивности дифракционных максимумов, ответственных за направления (100). Нанесение пленки $\mathrm{ZnO}$ на подложку из полированной керамики ЦТСЛ не вызывало смещение дифракционного пика (100) в сравнении с положением аналогичного пика на дифрактограмме структуры $\mathrm{ZnO}-\mathrm{SiO}_{2}$.

Наибольшая интенсивность дифракционных максимумов (002) наблюдается у структуры $\mathrm{ZnO}-$ кварц, что свидетельствует о наибольшем совершенстве синтезированного слоя $\mathrm{ZnO}$ по сравнению со слоем оксида цинка, нанесенном на поверхность сегнетоэлектрической керамики ЦТСЛ.

На дифрактограммах сдвиги положения максимумов и изменение их интенсивности могут происходить из-за увеличения межплоскостного расстояния, которое обусловлено упругими растягивающими напряжениями, возникающими при синтезе пленки $\mathrm{ZnO}$ на подложках из полированной керамики ЦТСЛ.

По данным рентгеноструктурного анализа все синтезируемые пленки имеют нанокристаллическую структуру. Размеры кристаллов в слое $\mathrm{ZnO}$ структуры $\mathrm{ZnO-ЦТСЛ,} \mathrm{вычисленные} \mathrm{по} \mathrm{формуле} \mathrm{Селякова-Шер-}$ pepa [5], не превышали $23 \mathrm{~nm}$, а размеры нанокристаллов в слое $\mathrm{ZnO}$, нанесенного на кварцевую подложку, не превышали $15 \mathrm{~nm}$. Увеличение в полтора раза размеров нанокристаллов оксида цинка в структуре $\mathrm{ZnO}-$ ЦТСЛ по сравнению с размерами нанокристаллов $\mathrm{ZnO}$ в структуре $\mathrm{ZnO}-$ кварц, скорее всего, обусловлено наличием у керамической подложки структурного разупорядочения, характерного для керамических материалов.

Сравнение литературных данных о характере дифрактограмм пленок $\mathrm{ZnO}$, синтезированных высокочастотным (ВЧ) распылением мишени из керамики $\mathrm{ZnO}$ [4], с результатами рентгеноструктурного анализа, приведенными выше, показывает корреляцию в положении пика (002) дифрактограмм во всех случаях. Кроме того, совместный анализ вида дифрактограмм пленок, синтезированных методом импульсного электронно-лучевого напыления и методом ВЧ распыления, показывает отсутствие дифракционных максимумов (100), (101), (102), (110) на дифрактограммах образцов, изготовленных методом ВЧ распыления. Минимальные размеры нанокристаллов $\mathrm{ZnO}$, синтезированных на кварцевых подложках обоими методами, практически совпадают.

Исследования спектров пропускания и отражения проводились в диапазоне длин волн от 300 до $800 \mathrm{~nm}$ на спектрометре Perkin Elmer Lambda 650. Измерения проводились при комнатной температуре. Спектры пропускания оксида цинка приведены на рис. 2. Из графика спектра пропускания видно, что в диапазоне длин волн $400-800 \mathrm{~nm}$ коэффициент пропускания $(T)$ находится в диапазоне от 40 до $84 \%$. На графике спектра пропускания видны осцилляции, обусловленные эффектом интерференции в тонкой пленке. Спектральная зависимость коэффициента пропускания, коэффициента поглощения и показателя преломления пленки в области длин волн, где эффект интерференции не наблюдается, связаны 


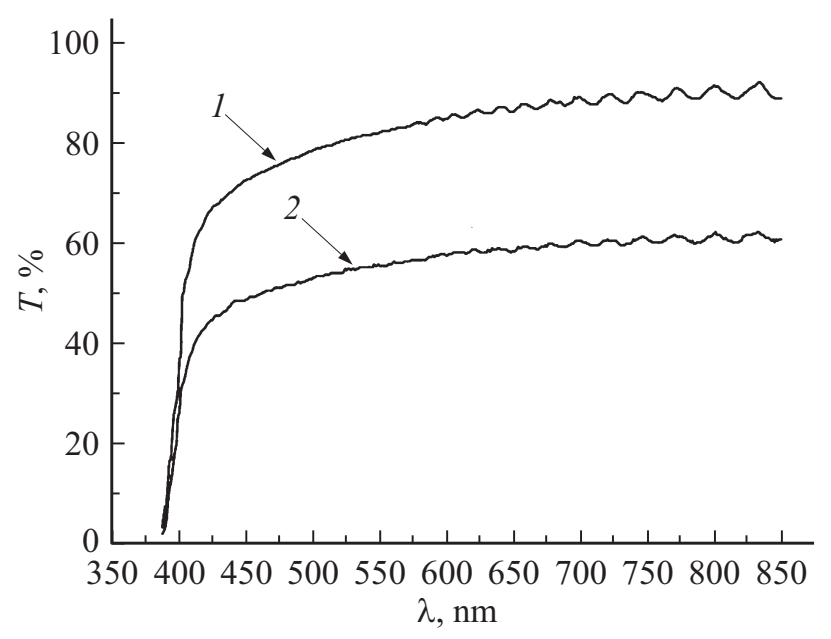

Рис. 2. Спектры пропускания пленки $\mathrm{ZnO}$ в структурах $\mathrm{ZnO}-$ кварц (1) и $\mathrm{ZnO}-$ ЦТСЛ (2).

соотношением $[6,7]$

$$
T_{0}=\frac{(1-R)^{2}\left[1+\left(\frac{\lambda \alpha}{4 \pi n}\right)^{2}\right]}{\exp (\alpha d)-R^{2} \exp (-\alpha d)} .
$$

Спектральная зависимость коэффициента пропускания пленки при наличии эффекта интерференции имеет вид [6]

$$
T=\frac{\left(1-R_{12}\right)^{2}}{1+R_{12}^{2}-2 R_{12} \cos (4 \pi n d / \lambda)},
$$

где $R_{12}=\left(\frac{n-1}{n+1}\right)^{2}$.

Выражение для показателя преломления пленки $[6,7]$

$$
n=\frac{\lambda_{m} \lambda_{m-1}}{2 d\left[\lambda_{m-1}-\lambda_{m}\right]} .
$$

Соотношение коэффициентов пропускания в минимуме и в максимуме при наличии интерференции может быть представлено в виде соотношения [6]

$$
\frac{T_{\min }}{T_{\max }}=\left(\frac{2 n}{n^{2}+1}\right)=T_{0}^{2} .
$$

Спектр отражения пленок $\mathrm{ZnO}$ приведен на рис. 3 . На спектре отражения также наблюдаются осцилляции, обусловленные эффектом интерференции света в тонких пленках. Таким образом, на основании совместных спектров пропускания и отражения с учетом анализа интерференционных полос в спектре пропускания и спектре отражения был определен показатель преломления для пленок оксида цинка, который составил 2.36 . Полученное значение показателя преломления близко к значениям, полученным для пленок оксида цинка, синтезированного реактивным магнетронным распылением [8].

Спектральная зависимость коэффициента поглощения $\mathrm{ZnO}$ была получена с помощью численного решения уравнений (1) и (2) с учетом соотношения (4). Затем для определения оптической ширины запрещенной зоны спектр поглощения пленки $\mathrm{ZnO}$ был перестроен в координатах $\left(\alpha^{2}-h v\right)$, и методом линеаризации переходной области была определена оптическая ширина запрещенной зоны. Она составила $3.29 \mathrm{eV}$ для пленки оксида цинка, нанесенной на поверхность кварцевой подложки. Величина оптической запрещенной зоны для пленки оксида цинка, нанесенной на поверхность сегнетокерамики ЦТСЛ, составила $3.26 \mathrm{eV}$.

Исследование люминесцентных свойств структур проводилось на люминесцентном спектрометре Perkin Elmer LS50B при комнатной температуре, длина волны возбуждающего излучения составляла $320 \mathrm{~nm}$. Спектры фотолюминесценции исследуемых структур приведены на рис. 4 (графики 1 и 2). На всех спектрах присутствует узкая интенсивная полоса люминесценции, находящаяся в УФ области около края собственного поглощения.

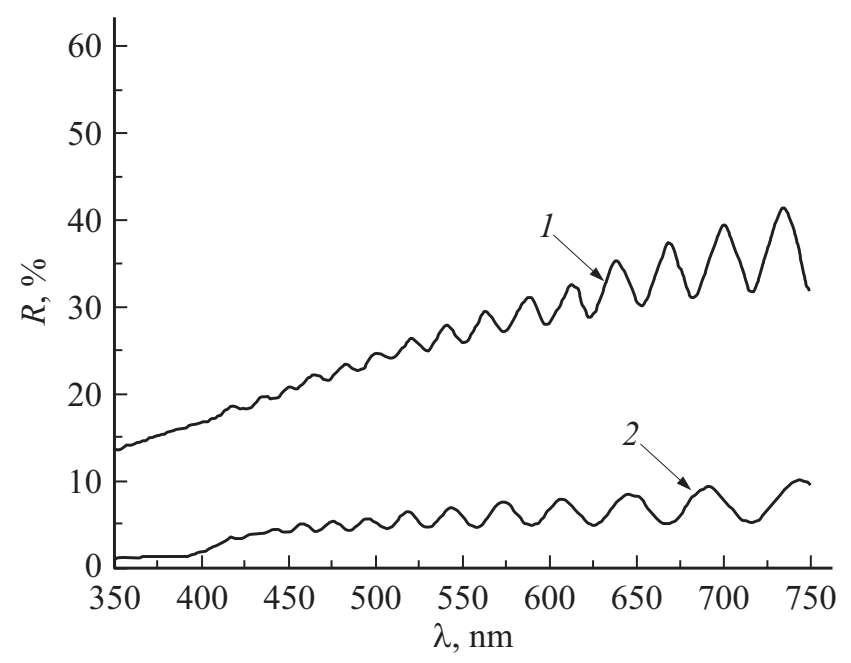

Рис. 3. Спектры отражения пленки $\mathrm{ZnO}$ в структурах $\mathrm{ZnO}-$ кварц (1) и $\mathrm{ZnO}-Ц$ ЦСЛ (2).

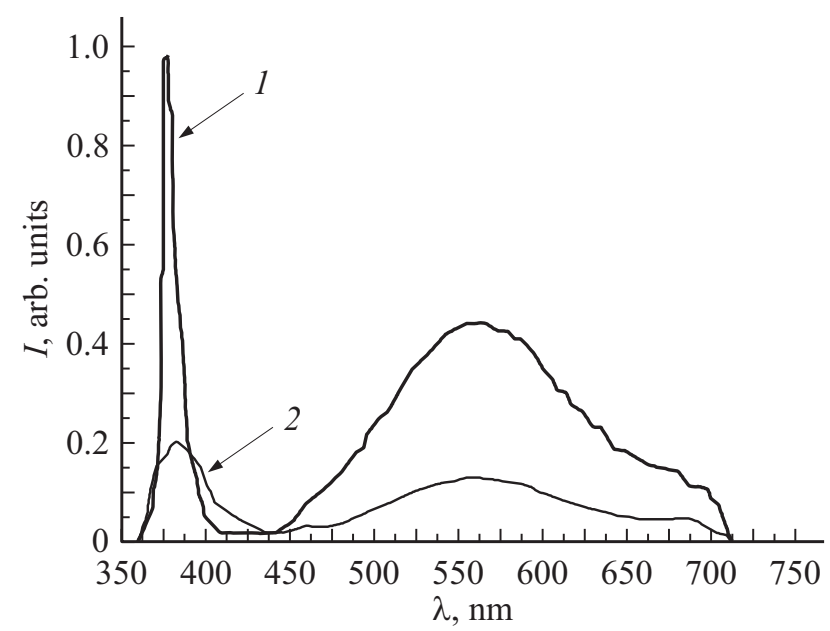

Рис. 4. Спектры фотолюминесценции структур: 1 -

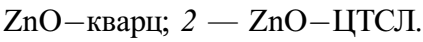


В литературе эта полоса фотолюминесценции называется краевой люминесценцией (КЛ) [9], которая обусловлена излучением различных экситонов Ванье-Мотта. Максимум полосы люминесценции, соответствующей слою $\mathrm{ZnO}$, нанесенному на поверхность $\mathrm{SiO}_{2}$ (рис. 4, график 1), находится на длине волны $377 \mathrm{~nm}$ и имеет полуширину $15 \mathrm{~nm}$. Согласно литературным данным, у монокристаллического оксида цинка в полосе от 370 до $367 \mathrm{~nm}$ расположены линии излучения донорно и акцепторно связанных экситонов [10]. Большая энергия связи экситона и очень быстрое время спада этой полосы люминесценции, составляющее единицы наносекунд, позволяет использовать ее для создания быстродействующих стинциляторов на основе $\mathrm{ZnO}$. Сдвиг в длинноволновую область максимума полосы УФ люминесценции при совпадающей одинаковой полуширине пика может быть объяснен поликристаллической структурой синтезированной пленки. Полоса УФ фотолюминесценции структуры $\mathrm{ZnO}-Ц$ ТСЛ (рис. 4, график 2) не совпадает по положению с предыдущей полосой, ее максимум сдвинут в область длинных волн и находится на длине волны $382 \mathrm{~nm}$. Кроме того, эта полоса имеет существенно меньшую интенсивность (в 5 раз менее интенсивная, чем полоса структуры $\mathrm{ZnO}-$ кварц), полуширина полосы составляет $28 \mathrm{~nm}$. Такое соотношение интенсивностей полос УФ фотолюминесценции двух исследуемых образцов может быть объяснено следующим образом: процессом, ответственным в исследуемой структуре за интенсивную фотолюминесценцию в УФ диапазоне спектра, является рекомбинация экситонов в объеме нанокристаллической пленки $\mathrm{ZnO}$, находящейся на поверхности сегнетоэлектрика $[11,12]$. В пользу этого утверждения свидетельствует положение узких полос фотолюминесценции в исследованных структурах в УФ диапазоне спектра, а также их сходство с экситонной полосой фотолюминесценции [9] монокристаллического оксида цинка. Значительно отличающаяся интенсивность полос УФ люминесценции позволяет предположить, что концентрации экситонов в слое полупроводника в структурах $\mathrm{ZnO}-\mathrm{SiO}_{2}$ и $\mathrm{ZnO}-Ц$ ТСЛ имеют существенно различные значения. Интенсивность полосы фотолю-

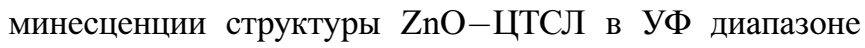
меньше в 5 раз интенсивности аналогичной полосы фотолюминесценции, структуры $\mathrm{ZnO}-$ кварц, это позволяет утверждать, что имеет место наибольшая концентрацию экситонов в объеме полупроводниковой пленки $\mathrm{ZnO}$, синтезированной на подложке из кварца. Энергия активации оптически активных ловушек, ответственных за полосу УФ люминесценции, находится в диапазоне от 3.29 до $3.32 \mathrm{eV}$. Эти значения близки к литературным данным для энергии активации ловушек в монокристаллическом оксиде цинка.

У всех исследуемых структур наблюдаются широкие полосы люминесценции, лежащие в сине-зелено-желтой спектральной полосе видимого диапазона. Кроме того, эти широкие полосы фотолюминесценции имеют сильно различающиеся значения полуширины и величины интенсивности. Интенсивность широкой полосы фотолюминесценции структуры $\mathrm{ZnO}-\mathrm{SiO}_{2}$ максимальна

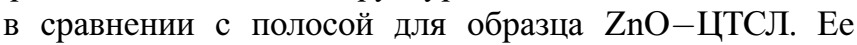
максимум находится на длине волны $559 \mathrm{~nm}$, а полуширина наибольшая из всех и составляет $124 \mathrm{~nm}$. Интенсивность этой широкой полосы больше в 4.5 раза интенсивности УФ полосы фотолюминесценции образца $\mathrm{ZnO}-Ц$ СС. Интенсивность широкой полосы фотолюминесценции образца $\mathrm{ZnO}-Ц$ ТСЛ наименее интенсивная. Максимум широкой полосы фотолюминесценции структуры $\mathrm{ZnO}-Ц$ ССЛ находится на длине волны $550 \mathrm{~nm}$ и имеет полуширину $78 \mathrm{~nm}$. График широкой полосы фотолюминесценции структуры $\mathrm{ZnO}-Ц$ ЦСЛ имеет симметричный вид относительно положения максимума: на нем присутствует область плавного нарастания и снижения интенсивности, которые могут быть обусловлены люминесценцией оптически активных дефектов с энергией активации от 2.48 до $1.97 \mathrm{eV}$. К таким дефектам, ответственным за фотолюминесценцию в этом спектральном диапазоне, можно отнести вакансии кислорода, вакансии цинка, межузельный кислород и межузельный цинк [10-15]. Эти дефекты образуются при импульсном электронно-лучевом испарении мишени из спрессованного порошка оксида цинка из-за нарушения стехиометрического состава оксида цинка. Энергия активации оптически активных дефектов и спектральное положение широких максимумов имеет корреляцию с литературными данными [12]. Согласно литературным данным, ответственными за полосу люминесценции с максимумом $492 \mathrm{~nm}$ являются вакансии кислорода [13]. Вакансии цинка ответственны за полосу люминесценции с максимумом $528 \mathrm{~nm}$ [13]. Различие интенсивностей широких полос фотолюминесценции может быть обусловлено различной концентрацией указанных типов ловушек в объеме пленки ZnO. Наибольшая концентрация ловушек наблюдается в слое $\mathrm{ZnO}$ у структуры $\mathrm{ZnO}-$ кварц.

\section{Выводы}

Методом импульсного электронно-лучевого распыления пленки $\mathrm{ZnO}$ из порошка оксида цинка удалось сформировать на поверхности полированных кварцевых пластин и полированных пластин из сегнетоэлектрической керамики ЦТСЛ тонкие наноструктурированные пленки $\mathrm{ZnO}$, содержащие малое количество структурных дефектов. Об этом свидетельствует интенсивный максимум (002) на дифрактограммах исследуемых пленок.

Интенсивность полосы УФ фотолюминесценции пленки $\mathrm{ZnO}$ на подложке из кварца наивысшая по сравнению со структурой $\mathrm{ZnO}-Ц$ ТСЛ. Интенсивность полосы фотолюминесценции в УФ области может быть связана с концентрацией экситонов в пленке оксида цинка. Интенсивность полосы фотолюминесценции определяется концентрацией экситонов в слое $\mathrm{ZnO}$, которая наиболее 
высока в структуре $\mathrm{ZnO}-$ кварц. Полосы люминесценции в сине-зеленой области видимого спектра, присутствующие в спектрах всех исследуемых структур, могут быть связаны с присутствием точечных дефектов в объеме пленки $\mathrm{ZnO}$, таких как вакансии кислорода, вакансии цинка, межузельный кислород и межузельный цинк. Различие интенсивности полос фотолюминесценции в сине-зелено-желтой области спектра обусловлено различной концентрацией ловушек в объеме пленки $\mathrm{ZnO}$.

Таким образом, пленки $\mathrm{ZnO}$, синтезированные методом импульсного электронно-лучевого испарения на поверхности кварца и сегнетоэлектрической керамики, могут быть использованы для создания фотолюминесцентных и фотоприемных структур, способных работать преимущественно в УФ диапазоне спектра.

\section{Конфликт интересов}

Авторы заявляют, что у них нет конфликта интересов.

\section{Список литературы}

[1] Wen-Che T., Hui-Ling K., Kun-Hsu L. // Optics Express. 2015. V. 23. Iss. 3. P. 2187-2195.

[2] Wei C.L., Chen Y.E., Cheng C.C. // Thin Solid Films. 2010. V. 518. N 11. P. 3059-3062.

[3] Вендик О.Г., Горин Ю.Н., Попов В.Ф. Корпускулярнофотонная технология. М.: Высшая Школа,1984. 239 с.

[4] Закирова А.Н., Крылов П.Н., Суворов И.А., Федотова И.В. // Вест. Удмуртского государственного университета. Сер. Физика конденсированного состояния вещества. 2012. B. 4. C. $14-17$.

[5] Русаков А.A. Рентгенография металлов. М.: Атомиздат, 1977. $480 \mathrm{c}$.

[6] Уханов Ю.И. Оптические свойства полупроводников. М.: Наука, 1977. 366 с.

[7] Алексеев С.А., Прокопенко В.Т., Яськов А.Д. Экспериментальная оптика полупроводников. СПб.: Политехника, 1994. $246 \mathrm{c}$.

[8] Веселов А.Г., Кирясова О.А., Сердобинцев А.А. // ФТП. 2008. T. 42. № 4. C. 496-499.

[9] Thomas D.G. // J. Phys. Chem. Solids. 1960. V. 15. P. 86-96.

[10] Berseth T. et al. // Appl. Phys. Lett. 2006. V. 89. P. 262112.

[11] Bagnal D.M., Chen Z., Yao T. // Appl. Phys. Lett. 1998. V. 73. P. 1038-1040.

[12] Yao B.D., Chang V.F., Wang F. // Appl. Phys. Lett. 2002. V. 81. N 4. P. 757-759.

[13] Ton-That C. // Phys. Rev. B. 2012. V. 86. P. 115205.

[14] Грузинцев А.Н., Волков В.Т. // ФТП. 2011. Т. 45. В. 11. C. $1476-1480$.

[15] Yao B.D., Chang V.F., Wang F. // Appl. Phys. Lett. 2002. V. 81. N 4. P. 757-759. 